\title{
Vitamin D Deficiency in Iran
}

\author{
Sedigheh Mirhashemi ${ }^{1, *}$, Mohammad Hossain Kalantar Motamedi ${ }^{1}$, Amir Hossain Mirhashemi ${ }^{2}$, Hamidreza \\ Taghipour ${ }^{1}$, Zahra Danial ${ }^{1}$ \\ 1 Trauma Research Center, Baqiyatallah University of Medical Sciences, Tehran, Iran \\ ${ }^{2}$ Department of Orthodontics, School of Dentistry, Tehran University of Medical Sciences, Tehran, Iran
}

Corresponding Author: Sedigheh Mirhashemi, Trauma Research Center, Baqiyatallah University of Medical Sciences, Tehran, Iran. Tel: +98-2188053766, E-mail: sedmir54@yahoo.com

Received June 2, 2017; Accepted June 15, 2017; Online Published August 29, 2017

$\mathrm{V}$ itamin D plays a basic role in bone growth and metabolism and has been noted for its important role in many diseases. Vitamin D deficiency causes a delay in growth during embryonic and childhood periods. It also causes skeletal deformity and increases the risk of hip fracture. The prevalence of vitamin $\mathrm{D}$ deficiency differs among different sex and age groups in developing countries. Iran is a country with a high prevalence of moderate to severe vitamin $\mathrm{D}$ deficiency. The highest prevalence of moderate to severe vitamin $\mathrm{D}$ deficiency in men was observed in Tehran, while Mashhad and Bushehr had the lowest prevalence rates among both men and women. ${ }^{1}$ The prevalence rates of mild, moderate, and severe vitamin $\mathrm{D}$ deficiencies among the adult population were $19.6 \%, 23.9 \%$, and $26.7 \%$, respectively. The prevalence of vitamin D deficiency was high even in the sunny city of Isfahan, particularly among women and younger populations. This result emphasizes the necessity of vitamin D supplementation as exposure to sunlight is limited by the type of clothing required by current law. ${ }^{2}$ Vitamin D deficiency was seen in $75.1 \%$ of women and $72.1 \%$ of men. Its high prevalence rate in Iran is similar to those reported by other studies in the Middle East. ${ }^{3}$ People pay more for cosmetics and clothes than they do for food and health. People must be convinced that replacing unhealthy foods with healthy ones is essential if they want to be healthy. Despite the World Health Organization's recommendation that annual per capita milk consumption should be at least 165 kilograms, consumption is about 85-90 kilograms in Iran. Vitamin $\mathrm{D}$ deficiency is common in various cities located at sea level and in cities with lower geographic latitudes. It is a common medical problem, afflicting an estimated one billion people throughout the world. The prevalence of vitamin $\mathrm{D}$ deficiency in countries where food is enriched by vitamin D (Scandinavian countries) is $1.6-14.8 \%{ }^{4}$. In other European countries, the prevalence rate among middle-aged and elderly people ranges between 14$59.6 \%$. In Tunisia, it is $47.6 \%$, and among teenagers in Boston, Massachusetts, USA it is $24.1 \%$. Vitamin D deficiency is much more prevalent in Asia. A total of 30$50 \%$ of people in India, Lebanon, and Turkey, and also $45.2 \%$ of females in China were found to be vitamin D deficient. Several studies in different parts of Iran and among different age groups have shown a high prevalence of vitamin D deficiency. ${ }^{5}$ Its prevalence in Tehran (the capital city of Iran) was $60 \%$ in males and $91 \%$ in females. Another study in different cities of Iran with different climates showed that $27.2 \%$ of females and $37.25 \%$ of males had mild vitamin D deficiency, and $47.85 \%$ of females and $34.75 \%$ of males had moderate to severe vitamin $\mathrm{D}$ deficiency. Those figures confirm the results of the present study. ${ }^{6}$ It is recommended that efforts be made to encourage people to take vitamin D and calcium supplements and to have more exposure to sunlight. The distribution of milk in schools will be effective in standardizing and promoting the habit of drinking milk in the society.

\section{Authors' Contributions}

All authors contributed equally to this study.

\section{Conflict of Interest Disclosures}

The authors declare that they have no conflicts of interest.

\section{Funding}

None.

\section{References}

1. Heshmat R, Mohammad K, Majdzadeh S, Forouzanfar M, Bahrami A, Ranjbar Omrani G. Vitamin D deficiency in Iran:

Copyright $\odot 2017$ The Author(s). This is an open-access article distributed under the terms of the Creative Commons Attribution License (http://creativecommons.org/licenses/by/4.0), which permits unrestricted use, distribution, and reproduction in any medium, provided the original work is properly cited. 
A multi-center study among different urban areas. Iran J Public Health. 2008;37(suppl).

2. Hovsepian S, Amini M, Aminorroaya A, Amini P, Iraj B. Prevalence of vitamin $D$ deficiency among adult population of Isfahan City, Iran. J Health Populat Nutr. 2011;29(2):149.

3. Moradzadeh K, Larijani B, Keshtkar A, Hossein-Nezhad A Rajabian R, Nabipour I, et al. Normative values of vitamin D among Iranian population: a population based study. Int J Osteop Metab Disord. 2008;1(1):8-15.

4. Burnand B, Sloutskis D, Gianoli F, Cornuz J, Rickenbach M, Paccaud F, et al. Serum 25-hydroxyvitamin D: distribution and determinants in the Swiss population. Am J Clin Nutr. 1992;56(3):537-42. doi: 10.1093/ajen/56.3.537. pmid: 1503066.

5. Azizi F, Rais-Zadeh F, Mir Said Ghazi A. Vitamin D deficiency in a group of Tehran Population. Res Med 2000;4:291-303.

6. Moradzadeh K, Keshtkar A, Hossein Nezhad A, Rajabian R, Nabipour I, Omrani G, et al. Normal values of vitamin D and prevalence of vitamin D deficiency among Iranian population. Sci Kurdistan Med Univ. 2006;10(4):33-43.

Citation: Mirhashemi S, Kalantar Motamedi MH, Mirhashemi AH, Taghipour H, Danial Z. Vitamin D deficiency in Iran. Int J Med Rev. 2017;4(3):64-65. doi: 10.29252/ijmr-040301. 